\title{
Atividade das fosfodiesterases em tecido de granulação submetido a irradiação de elétrons - estudo experimental em ratos
}

\section{Activity of phosphodiesterases in granulation tissue submitted to electron irradiation - experimental study in rats}

\author{
Frab Norberto BÓSCOLO* \\ Solange Maria de ALMEIDA** \\ Jaime Aparecido CURY*** \\ Roberto Martins LOURENÇO****
} BÓSCOLO, F. N.; ALMEIDA, S. M. de; CURY, J. A.; LOURENÇO, R. M. Atividade das fosfodiesterases em tecido de gra-
nulação submetido a irradiação de elétrons - estudo experimental em ratos. Pesqui Odontol Bras, v. 15, n. 3 ,
p. $223-228$, jul./set. 2001.

\begin{abstract}
Os autores estudaram o efeito de baixas doses de radiação de elétrons na atividade de fosfodiesterases presentes no tecido de granulação, induzido por esponja de PVC, subcutaneamente, na região dorsal de 84 ratos Wistar, divididos em dois grupos, controle e irradiado. A atividade enzimática foi avaliada segundo a evolução do tecido de granulação aos 5, 7, 10, 14, 17, 20 e 24 dias. Os animais foram irradiados com um feixe de elétrons de $6 \mathrm{MeV}$, dose de 1 Gy, 3 dias após a implantação da esponja, sendo que no momento da irradiação, foram protegidos por uma lâmina de $4 \mathrm{~mm}$ de chumbo, tendo sido irradiada somente a área correspondente ao local onde encontrava-se a esponja. Considerando-se a dose e o tipo de radiação empregada, pode-se concluir que houve influência direta da radiação na atividade da enzima 5'-nucleotidase e da ATPase no início do processo de reparação tecidual, aos 5 e 7 dias. Já a enzima fosfatase alcalina não sofreu a ação direta da radiação. É possivel que o principal fator tenha sido danos nos constituintes celulares que são responsáveis pela formação do tecido de granulação, determinando a produção enzimática conforme a necessidade.
\end{abstract}

UNITERMOS: Radiação; Elétrons; Tecido de granulação; Enzimas; Fosfatase alcalina; Adenosinatrifosfatase; 5'-nucleotidase.

\section{INTRODUÇÃO}

O efeito das radiações ionizantes, decorrente de sua interação com os tecidos vivos, é assunto de grande interesse, visto que o seu uso tornou-se imprescindivel, seja no diagnóstico ou na terapêutica. Dentre essas, a radiação por elétrons é muito utilizada no tratamento de lesões superficiais ou de média profundidade ${ }^{10,25}$, como micoses causadas por fungos, por ser possivel controlar o poder de penetração do feixe de elétrons.

Algumas vezes, a associação radioterapia/cirurgia é necessária ${ }^{7,8}$. Portanto, é importante avaliar o comportamento de elementos que contribuem para o processo de reparação tecidual, quando submetidos à ação de radiação ionizante.

Pesquisas avaliando a ação da radiação $\mathrm{X}$ e de elétrons nos tecidos vivos têm sido realiza$\operatorname{das}^{1,2,3,4,5,6,611,14,15,17,21,23,24}$. Entretanto, a ação de baixas doses de radiação de elétrons no processo de reparação tecidual é pouco estudada ${ }^{3}$, não sendo avaliados elementos específicos como as enzimas, que têm um importante papel no desenvolvimento do tecido neoformado. Dentre as fosfoesterases, três enzimas participam ativamente na formação do tecido de granulação: a fosfatase alcalina, intimamente relacionada ao processo de agregação do colágeno sob a forma de feixes através das glicosaminoglicanas, agindo na formação das cadeias de carboidratos; a 5'-nucleotidase que tem sua atividade seqüenciada com a síntese de colágeno e glicosaminoglicanas; e a adenosina trifosfatase (ATPase) que é essencial à síntese de colágeno e glicosaminoglicanas ${ }^{23}$.

*Professor Titular da Área de Radiologia; **Professora Assistente Doutora da Área de Radiologia; ***Professor Titular da Área de

Bioquímica - Faculdade de Odontologia de Piracicaba da UNICAMP.

*****Professor Responsável pela Disciplina de Radiologia da Faculdade de Odontologia de Alfenas. 
BÓSCOLO, F. N.; ALMEIDA, S. M. de; CURY, J. A.; LOURENÇO, R. M. Atividade das fosfodiesterases em tecido de granulação submetido a irradiação de elétrons - estudo experimental em ratos. Pesqui Odontol Bras, v. 15, n. 3, p. 223-228, jul./set. 2001.

O processo de reparação tecidual inicia-se com a formação do tecido de granulação, tendo como principal característica vasos neoformados e fibroplasia. A organização tecidual é resultado da produção de colágeno e moléculas de glicosaminoglicanas pelos fibroblastos ${ }^{18}$. À medida que o tecido torna-se maduro, o número de vasos e células diminui, predominando a agregação de fibras colágenas sob a forma de feixes. Como a fosfatase alcalina, a 5'-nucleotidase e a adenosina trifosfatase participam no processo de reparação tecidual, propõe-se avaliar o efeito de baixas doses de radiação de elétrons na atividade dessas enzimas.

\section{MATERIAIS E MÉTODOS}

Foram utilizados 84 ratos Wistar, machos, pesando entre 180 e 300 gramas, com idade entre 60 e 90 dias. Após anestesia intraperitoneal com pentabarbital sódico, foi implantado um disco de esponja de polivinil, para produção do tecido de granulação. Os animais foram divididos, aleatoriamente, em dois grupos: controle e irradiado. A irradiação foi realizada com um acelerador linear, modelo Mevatron 74 (Siemens) com feixe de elétrons com energia de $6 \mathrm{MeV}$, a uma distância fonte-pele de $100 \mathrm{~cm}$ e dose simples de 1,0 Gy. Somente a área correspondente ao local onde encontrava-se implantada a esponja foi irradiada, sendo o restante do corpo do animal protegido por uma lâmina de chumbo com 4,0 $\mathrm{mm}$ de espessura.

Nos tempos de 5, 7, 10, 14, 17, 20 e 24 dias, o tecido de granulação foi removido, lavado em soro fisiológico, pesado e mantido a baixa temperatura até a extração enzimática, na qual se utilizou solução tampão constituída de Tris- $\mathrm{HCl} 0,1 \mathrm{M}$, mercaptoetanol $1 \mathrm{mM}$, EDTA $1 \mathrm{mM}$ pH 7,4 ${ }^{19}$. Para cada $100 \mathrm{mg}$ de tecido, acrescentou-se $1,0 \mathrm{ml}$ de tampão e realizou-se a homogeneização em homogeneizador tipo Potter-Elvehgen. O extrato foi centrifugado a 11.000 giros por 2 minutos e o sobrenadante foi utilizado para determinar a atividade enzimática. A atividade da fosfatase alcalina foi determinada pelo método de KELLY; BUTLER ${ }^{12}$ (1975) usando-se como substrato p-nitrofenilfosfato. A atividade da 5'-nucleotidase foi determinada segundo KELLY et al. ${ }^{13}$ (1975) e da adenosina trifosfatase segundo SEIDEL; GERGELY ${ }^{20}$ (1963).

Para as enzimas fosfatase alcalina e 5'-nucleotidase, a atividade enzimática foi a quantidade de enzima capaz de liberar $1 \mu \mathrm{g}$ de produto/min. a $30^{\circ} \mathrm{C}$. Para a ATPase, foi a quantidade de enzima capaz de liberar $1 \mu \mathrm{g}$ de fósforo/min. a $30^{\circ} \mathrm{C}$.
A medição da quantidade de proteína dos extratos foi feita contra padrão de proteína de $100 \mu \mathrm{g} / \mathrm{ml}$, através do método de LOWRY et al. ${ }^{16}$ (1951).

\section{RESULTADOS}

Os resultados obtidos foram submetidos a tratamento estatístico pelo teste de Tukey, em nivel de $1 \%$, para os grupos dentro de cada período de tempo e à regressão polinomial para os tempos dentro de cada grupo.

\section{DISCUSSÃO}

O tecido de granulação, induzido pela implantação de esponja, inicia sua formação por volta do terceiro e quarto dias. A formação desse tecido corresponde à fase inicial para que uma região lesada do organismo restabeleça, se não total, pelo menos parcialmente as suas funções através do processo de reparo. Este processo é caracterizado pela síntese de colágeno e glicosaminoglicanas pelos fibroblastos. Segundo ROSS ${ }^{18}$ (1965), a produção de colágeno inicia-se a partir de 15 minutos após a injúria, sendo detectável de 4 a 7 dias de desenvolvimento do tecido. Já as moléculas de glicosaminoglicanas, podem ser encontradas nas primeiras 24 horas, começando realmente a sintese do segundo ao quarto dia. Como apresentado por VIZIOLI $^{22}$ (1975), as três enzimas estudadas têm participação ativa na formação do tecido de granulação, estando portanto condicionadas ao desenvolvimento da síntese de colágeno e glicosaminoglicanas.

Avaliando-se a Tabela 1 e o respectivo Gráfico 1, observa-se que até os 10 dias de evolução do tecido de granulação, a fosfatase alcalina apresentou maior atividade no grupo irradiado. Como a radiação causa danos ao processo de reparo, como demonstraram WATANABE et al. ${ }^{24}$ (1994) e ALMEIDA $^{3}$ (1997), sendo que ALMEIDA ${ }^{3}$ (1997) usou a mesma dose e tipo de radiação que aquela utilizada nesta pesquisa, pode-se deduzir que a maior atividade da fosfatase alcalina nesse grupo foi decorrente do fato de a fase inflamatória no grupo irradiado ter sido mais intensa. Do $14^{\circ}$ dia de evolução do tecido de granulação até o $24^{\circ}$ dia, observa-se que ocorre uma inversão na atividade da fosfatase alcalina, quando comparados os dois grupos, sendo que no grupo irradiado, a atividade dessa enzima apresentou-se menor, porém não houve diferença estatisticamente significante en- 
BÓSCOLO, F. N.; ALMEIDA, S. M. de; CURY, J. A.; LOURENÇO, R. M. Atividade das fosfodiesterases em tecido de granulação submetido a irradiação de elétrons - estudo experimental em ratos. Pesqui Odontol Bras, v. 15, n. 3, p. 223-228, jul./set. 2001.

TABELA 1 - Média e desvios-padrão da atividade da fosfatase alcalina, em todos os tempos analisados.

\begin{tabular}{l|c|c}
\hline \multicolumn{1}{c|}{ Grupos } & Média & Desvio-padrão \\
\hline Controle -5 dias & $1,44 \mathrm{~A}$ & 0,11 \\
\hline Irradiado -5 dias & $1,66 \mathrm{~A}$ & 0,35 \\
\hline Controle -7 dias & $0,94 \mathrm{~A}$ & 0,27 \\
\hline Irradiado -7 dias & $1,16 \mathrm{~A}$ & 0,63 \\
\hline Controle -10 dias & $1,96 \mathrm{~A}$ & 0,23 \\
\hline Irradiado -10 dias & $2,06 \mathrm{~A}$ & 0,49 \\
\hline Controle -14 dias & $2,01 \mathrm{~A}$ & 0,12 \\
\hline Irradiado -14 dias & $1,85 \mathrm{~A}$ & 0,18 \\
\hline Controle -17 dias & $2,01 \mathrm{~A}$ & 0,27 \\
\hline Irradiado -17 dias & $1,54 \mathrm{~A}$ & 0,13 \\
\hline Controle -20 dias & $1,80 \mathrm{~A}$ & 0,277 \\
\hline Irradiado -20 dias & $1,59 \mathrm{~A}$ & 0,31 \\
\hline Controle -24 dias & $2,08 \mathrm{~A}$ & 0,48 \\
\hline Irradiado -24 dias & $1,77 \mathrm{~A}$ & 0,40 \\
\hline \hline
\end{tabular}

Médias seguidas de letras iguais não diferem entre si pelo teste de Tukey $(\mathrm{p}<0,05)$.

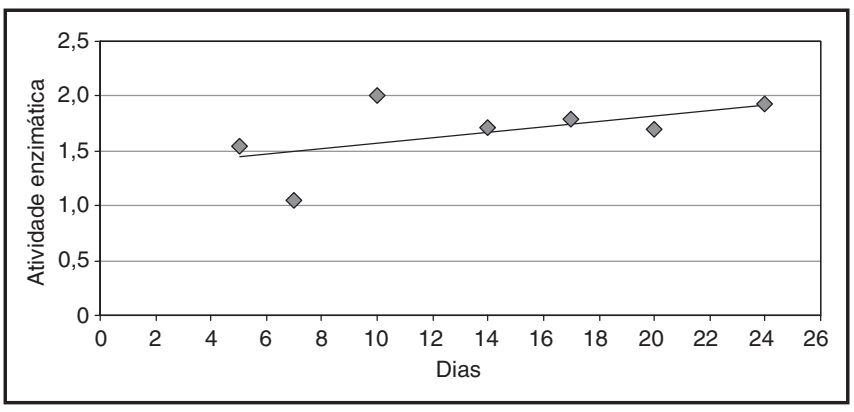

GRÁFICO 1 - Regressão polinomial referente à atividade da fosfatase - grupos controle e irradiado $\left(R^{2}=0,3039\right)$.

tre os grupos estudados, notando-se que houve uma tendência de comportamento bastante semelhante na atividade dessa enzima.

A atividade da 5'-nucleotidase mostrou-se maior no grupo irradiado em quase todos os tempos, apresentando uma diferença estatisticamente significante no $5^{\circ}$ e $7^{\circ}$ dias do experimento, sendo que somente no $17^{\circ}$ dia, o grupo controle apresentou maior atividade; porém, nota-se que do $10^{\circ}$ ao $24^{\circ}$ dia não houve diferença estatisticamente significante na atividade dessa enzima nos grupos estudados, como pode-se observar na Tabela 2 e nos Gráficos 2 e 3. Observa-se, contudo, uma tendência no comportamento da atividade da enzima
TABELA 2 - Média e desvios-padrão da atividade da 5'-nucleotidase, em todos os tempos analisados.

\begin{tabular}{l|c|c}
\hline \hline \multicolumn{1}{c|}{ Grupos } & Média & Desvio-padrão \\
\hline Controle -5 dias & $1,07 \mathrm{~B}$ & 0,15 \\
\hline Irradiado -5 dias & $1,66 \mathrm{~A}$ & 0,24 \\
\hline Controle -7 dias & $1,43 \mathrm{~B}$ & 0,14 \\
\hline Irradiado -7 dias & $1,93 \mathrm{~A}$ & 0,40 \\
\hline Controle -10 dias & $1,44 \mathrm{~A}$ & 0,34 \\
\hline Irradiado -10 dias & $1,66 \mathrm{~A}$ & 0,19 \\
\hline Controle -14 dias & $1,00 \mathrm{~A}$ & 0,15 \\
\hline Irradiado -14 dias & $1,25 \mathrm{~A}$ & 0,27 \\
\hline Controle -17 dias & $1,15 \mathrm{~A}$ & 0,18 \\
\hline Irradiado -17 dias & $0,95 \mathrm{~A}$ & 0,17 \\
\hline Controle -20 dias & $1,18 \mathrm{~A}$ & 0,29 \\
\hline Irradiado -20 dias & $1,22 \mathrm{~A}$ & 0,10 \\
\hline Controle -24 dias & $1,34 \mathrm{~A}$ & 0,22 \\
\hline Irradiado -24 dias & $1,46 \mathrm{~A}$ & 0,35 \\
\hline \hline
\end{tabular}

Médias seguidas de letras iguais não diferem entre si e médias seguidas de letras diferentes diferem entre si pelo teste de Tukey $(\mathrm{p}<0,05)$.

5'-nucleotidase nos dias estudados no grupo irradiado, não sendo encontrado no grupo controle, sugerindo que o fator tempo não influencia a atividade enzimática desse grupo. Analisando-se a atividade dessa enzima, observa-se que os resultados assemelham-se com aqueles apresentados por TOSONI et al. ${ }^{21}$ (1992), exceção feita para o $5^{\circ}$ e $7^{\circ}$ dias.

A atividade da ATPase mostrou-se menor no $5^{\circ}$ dia de evolução do tecido de granulação no grupo controle, sendo que a diferença em relação ao grupo irradiado foi significante. Nos demais tempos estudados, a atividade dessa enzima foi maior no grupo controle, como pode-se observar na Tabela 3; porém, a diferença entre os grupos não foi estatisticamente significante e com uma tendência de comportamento da atividade da ATPase muito semelhante nos dois grupos, como mostram os Gráficos 4 e 5 . Já TOSONI et al. ${ }^{21}$ (1992) observaram menor atividade dessa enzima no $7^{\circ}$ dia do experimento, contudo a dose foi menor e a radiação empregada foi a radiação $\mathrm{X}$. Segundo VIZIOLI ${ }^{22}$ (1975), essa enzima está relacionada com o papel do ATP como fonte de energia para os processos de síntese do tecido em desenvolvimento. Isso poderia explicar o fato de a 
BÓSCOLO, F. N.; ALMEIDA, S. M. de; CURY, J. A.; LOURENÇO, R. M. Atividade das fosfodiesterases em tecido de granulação submetido a irradiação de elétrons - estudo experimental em ratos. Pesqui Odontol Bras, v. 15, n. 3, p. 223-228, jul./set. 2001.

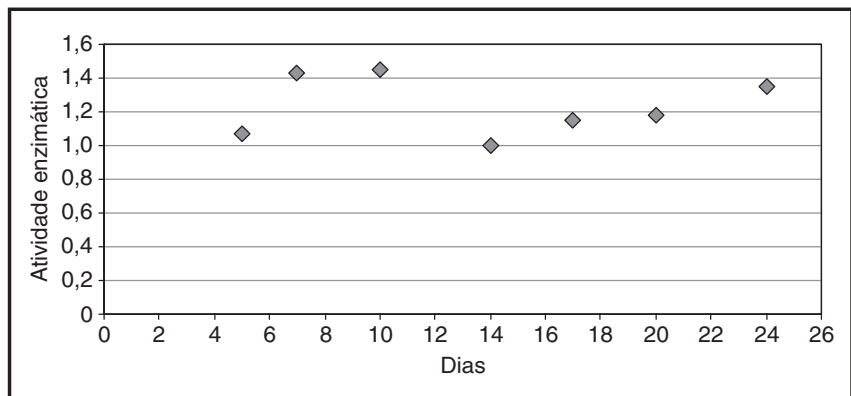

GRÁFICO 2 - Regressão polinomial referente à atividade da 5'-nucleotidase - grupo controle.

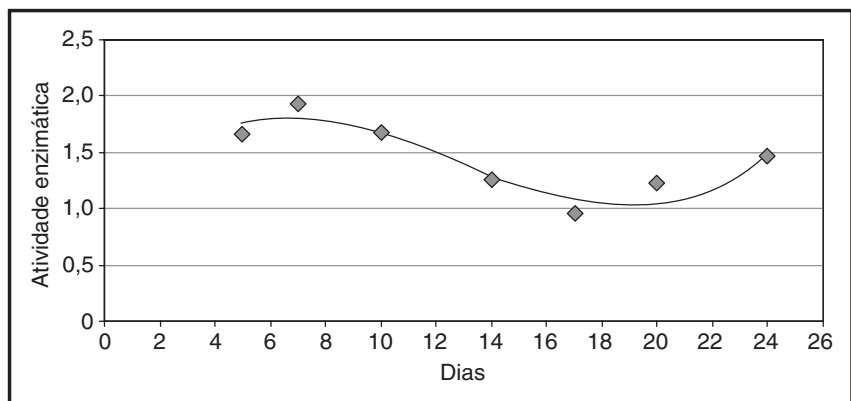

GRÁFICO 3 - Regressão polinomial referente à atividade da 5'-nucleotidase - grupo irradiado $\left(R^{2}=0,8799\right)$.

TABELA 3 - Média e desvios-padrão da atividade da ATPase, em todos os tempos analisados.

\begin{tabular}{l|c|c}
\hline \hline \multicolumn{1}{c|}{ Grupos } & Média & Desvio-padrão \\
\hline Controle -5 dias & $3,27 \mathrm{~B}$ & 0,34 \\
\hline Irradiado -5 dias & $4,78 \mathrm{~A}$ & 0,26 \\
\hline Controle -7 dias & $6,68 \mathrm{~A}$ & 0,45 \\
\hline Irradiado -7 dias & $5,87 \mathrm{~A}$ & 1,24 \\
\hline Controle -10 dias & $4,69 \mathrm{~A}$ & 0,49 \\
\hline Irradiado -10 dias & $4,61 \mathrm{~A}$ & 0,46 \\
\hline Controle -14 dias & $4,74 \mathrm{~A}$ & 0,59 \\
\hline Irradiado -14 dias & $4,02 \mathrm{~A}$ & 0,38 \\
\hline Controle -17 dias & $4,71 \mathrm{~A}$ & 0,54 \\
\hline Irradiado -17 dias & $4,59 \mathrm{~A}$ & 0,72 \\
\hline Controle -20 dias & $5,01 \mathrm{~A}$ & 0,79 \\
\hline Irradiado -20 dias & $5,43 \mathrm{~A}$ & 0,46 \\
\hline Controle -24 dias & $4,92 \mathrm{~A}$ & 0,35 \\
\hline Irradiado -24 dias & $4,89 \mathrm{~A}$ & 0,68 \\
\hline \hline
\end{tabular}

Médias seguidas de letras iguais não diferem entre si e médias seguidas de letras diferentes diferem entre si pelo teste de Tukey $(\mathrm{p}<0,05)$.

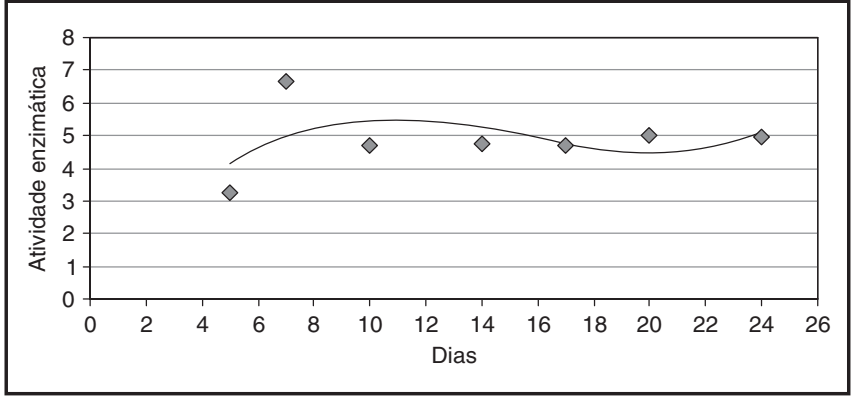

GRÁFICO 4 - Regressão polinomial referente à atividade da ATPase - grupo controle $\left(R^{2}=0,2069\right)$.

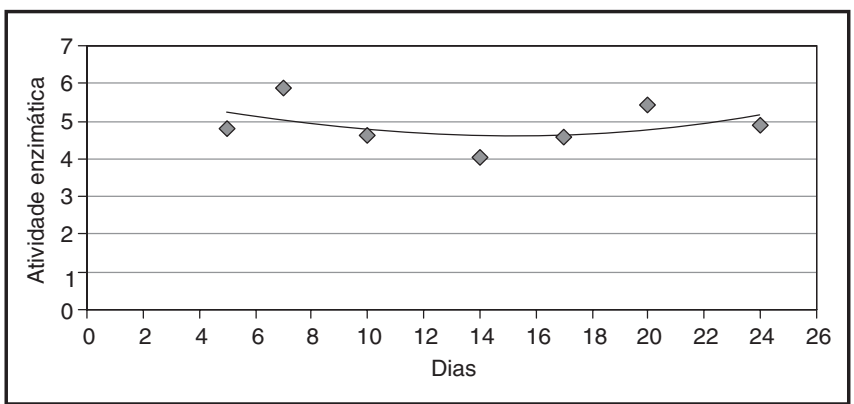

GRÁFICO 5 - Regressão polinomial referente à atividade da ATPase - grupo irradiado $\left(R^{2}=0,1676\right)$.

atividade da enzima ATPase ter sido maior, na maioria dos periodos avaliados, no grupo controle onde há maior síntese tecidual, enquanto no tecido irradiado, devido à ação da radiação, tem-se a presença de um maior número de radicais livres e conseqüentemente uma maior lentidão no processo de reparo, o que poderia justificar uma menor atividade, ainda que essa diferença de atividade, entre os grupos controle e irradiado, não tenha se mostrado estatisticamente significante. Pode-se observar também que o maior pico de atividade da ATPase ocorreu exatamente aos 7 dias de evolução do tecido de granulação, período correspondente ao início da neovascularização, o que está de acordo com os achados de VIZIOLI ${ }^{22}$ (1975) que cita estar essa enzima diretamente ligada às paredes dos vasos neoformados.

\section{CONCLUSÃO}

Pelos resultados desta pesquisa, as enzimas 5'-nucleotidase e ATPase tiveram sua atividade afetada diretamente pela radiação apenas no início do processo de reparação tecidual. Entretanto, a 
BÓSCOLO, F. N.; ALMEIDA, S. M. de; CURY, J. A.; LOURENÇO, R. M. Atividade das fosfodiesterases em tecido de granulação submetido a irradiação de elétrons - estudo experimental em ratos. Pesqui Odontol Bras, v. 15, n. 3, p. 223-228, jul./set. 2001.

fosfatase alcalina não sofreu ação direta da radiação. Talvez o principal fator tenha sido os danos causados nos constituintes celulares que são responsáveis pela formação do tecido de granulação, determinando a produção enzimática conforme a necessidade.

\section{AGRADECIMENTOS}

Os autores agradecem ao CNPq (Processo $\mathrm{n}^{\circ}$ 301185/95-6) e ao físico José Renato de Oliveira Rocha, do Centro de Engenharia Biomédica da UNICAMP.

BÓSCOLO, F. N.; ALMEIDA, S. M. de; CURY, J. A: LOURENCO, R. M. Activity of phosphodiesterases in granulation tissue submitted to electron irradiation - experimental study in rats. Pesqui Odontol Bras, v. 15, n. 3, p. 223-228, jul./set. 2001.

\begin{abstract}
The present study evaluated the effect of low doses of electron radiation on the activity of phosphodiesterases in granulation tissue. In order to induce growth of granulation tissue, a PVC sponge disk was introduced under the dorsal skin of 84 Wistar rats. The rats were divided in two groups, control and irradiated. The enzymatic activity was evaluated according to the evolution of the granulation tissue after 5, 7, 10, 14, 17, 20 and 24 days. Irradiation was carried out 3 days after the implantation of the sponge, by means of a linear accelerator, with energy of $6 \mathrm{MeV}$, and dose of $1.0 \mathrm{~Gy}$. The results of this study showed that 5'-nucleotidase and ATPase had their activity directly affected by irradiation only in the beginning of the tissue repairing process. Alkaline phosphatase did not suffer any direct effect of irradiation. It is possible that the main factor has been the damage of the cellular components responsible for the growth of granulation tissue, which determine the production of enzymes according to the necessity.
\end{abstract}

UNITERMS: Radiation; Electrons; Granulation tissue; Enzymes; Alkaline phosphatase; Adenosinetriphophatase; 5'-nucleotidase.

\section{REFERÊNCIAS BIBLIOGRÁFICAS}

1. ABDAlA, C. M.; VIZIOLI, M. R.; BÓSCOLO, F. N. et al. Estudo histológico da gênese e evolução do tecido de granulação sob efeito de baixas doses de radiação $X$. Rev Fac Odont Univ São Paulo, v. 5, n. 2, p. 90-95, jul./dez. 1991.

2. AITASALO, K. Effect of irradiation on early enzymatic changes in healing mandibular periosteum and bone. A histochemical study on rats. Acta Tadiol Oncol, v. 25, n. 3, p. 207-212, May/June 1986.

3. ALMEIDA, S. M. Efeito da radiação de elétrons na reparação tecidual. Piracicaba, 1997. 103 p. Tese (Doutorado) - Faculdade de Odontologia de Piracicaba, Universidade Estadual de Campinas.

4. BERNSTEIN, E. F.; SULLIVAN, F. J.; MITCHELL, J. B. et al. Biology of chronic radiation effect on tissues and wound healing. Cl Plast Surg, v. 20, n. 3, p. 435-453, July 1993.

5. BHATAVDEKAR, J. M.; CHINDY, N. J.; SHAH, V. C. A study on the levels of nucleic acids, protein and phosphatases in normal and X-irradiated guinea pigs. Strahlentherapie, v. 145, p. 83-87, 1973.

6. BÓSCOLO, F. N.; CURY, J. A.; GONÇALVES, N. Estudo da variação de enzimas, provocada pelo emprego da radiação no globo ocular de cães. Utilização de baixas doses e dosimetria termoluminescente. Rev Odont Univ São Paulo, v. 3, n. 2, p. 338-344, abr./jun. 1989.

7. DRAKE, D. B.; OISHI, S. N. Wound healing considerations in chemotherapy and radiation therapy. Clin Plast Surg, v. 22, n. 1, p. 31-37, Jan. 1995.

8. EHRLICHMAN, R. J.; SECKEL, B. R.; BRYAN, D. J. et al. Common complications of wound healing. Surg Clin North Am, v. 71, n. 6, p. 1323-1351, Dec. 1991.

9. FISKE, C. H.; SUBBAROW, Y. The colorimetric determina- tion of phosphorus. J Biol Chem, v. 66, p. 375-400, 1925.

10. FOWLER, J. F.; KRAGT, K.; ELLIS, R. E. et al. The effect of divided doses of $15 \mathrm{MeV}$ electrons on the skin response of mice. Int J Rad Biol, v. 9, n. 3, p. 241-252, Sept. 1965.

11. KAUR, A.; DUBEY, D. P.; GUPTA, G. S. Radiation effects on alkaline phosphatase and glucose-6-phosphatase in anatomically different regions of mouse intestine. Strahlentherapie, v. 50, p. 427-432, 1975.

12. KELLY, S. J.; BUTLER, L. G. Enzyme hydrolysis of phosphonate esters. Biochem Biophys Res Commun, v. 66, p. 316-321, 1975.

13. KELLY, S. J.; DARDINGER, D. E.; BUTLER, L. G. Hydrolysis of phosphonate esters catalysed by 5'-nucleotide phosphodiesterase. Biochemistry, v. 14, p. 4983-4988, 1975.

14. KRIZALA, J.; KUNA, P.; STOKLASOVA, A. et al. Influence of radioprotective agents on the activities of isoenzymes of blood serum alkaline phosphatase in irradiated dogs. Strahlentherapie, v. 156, p. 365-367, 1980.

15. LOURENÇO, R. M. Efeito de baixas doses de radiação $\mathbf{X}$ em feridas suturadas e não suturadas. Piracicaba, 1998. 93 p. Tese (Mestrado) - Faculdade de Odontologia de Piracicaba, Universidade Estadual de Campinas.

16. LOWRY, O. H.; ROSEBROUGH, N. J.; FARR, A. L. et al. Protein measurement with the folin phenol reagent. J Biol Chem, v. 193, p. 265-275, 1951.

17. MILLER, S. H.; RUDOLPH, R. Healing in the irradiated wound. Clin Plast Surg, v. 17, n. 3, p. 503-508, July 1990.

18. ROSS, R. Synthesis and secretion of collagen by fibroblasts in healing wounds. apud The use of radioautography in investigating protein synthesis. New York : Academic Press, 1965, p. 273-292. 
BÓSCOLO, F. N.; ALMEIDA, S. M. de; CURY, J. A.; LOURENÇO, R. M. Atividade das fosfodiesterases em tecido de granulação submetido a irradiação de elétrons - estudo experimental em ratos. Pesqui Odontol Bras, v. 15, n. 3, p. 223-228, jul./set. 2001.

19. SASSAKI, K. T.; NICOLAU, J. The effect of isoproterenol on some aspects of the anaerobic metabolism of carbohydrates in mouse submandibular gland. Gen Pharmacol, v. 13, p. 353-356, 1982.

20. SEIDEL, J. C.; GERGELY, J. Studies on myofibrillar adenosine triphosphatase with calcium-free adenosine triphosphatase. I - the effect of ethylenediaminetetraacetate, calcium, magnesium, and adenosine triphosphate. J Biol Chem, v. 238, p. 3648-3653, 1963.

21. TOSONI, G. M; BÓSCOLO, F. N.; CURY, J. A. et al. Estudo da atividade enzimática em tecidos de granulação de ratos submetidos a baixas doses de radiação. Rev Odont UNESP, v. 23, n. 1, p. 81-90, 1994.

22. VIZIOLI, M. R. Relação entre fosfomonoesterases e a sintese de colágeno e mucopolissacarídeos ácidos no tecido de granulação. Piracicaba, 1975, 61 p. Tese
(Livre-Docência) - Faculdade de Odontologia de Piracicaba, Universidade Estadual de Campinas.

23. WANG, Q.; DICKSON, G. R.; ABRAM, W. P. et al. Electron irradiation slows down wound repair in rat skin: a morphological investigation. Brit J Dermatol, v. 130, p. 551-560, 1994.

24. WATANABE, P. C. A.; VIZIOLI, M. R.; BÓSCOLO, F. N. et al. Efeitos de baixas doses de radiação sobre a gênese e evolução do tecido de granulação. Rev Odontol Univ São Paulo, v. 8, n. 2, p. 137-143, abr./jun. 1994.

25. WILLIANS, P. C.; HUNTER, R. D.; JACKSON, S. M. Whole body electron therapy in mycosis fungoides - a successful translational technique achieved by modification of an established linear accelerator. Brit J Radiol, v. 52, n. 616, p. 302-307, Apr. 1979.

Recebido para publicação em 21/07/00 Enviado para reformulação em 14/02/01

Aceito para publicação em 23/04/01

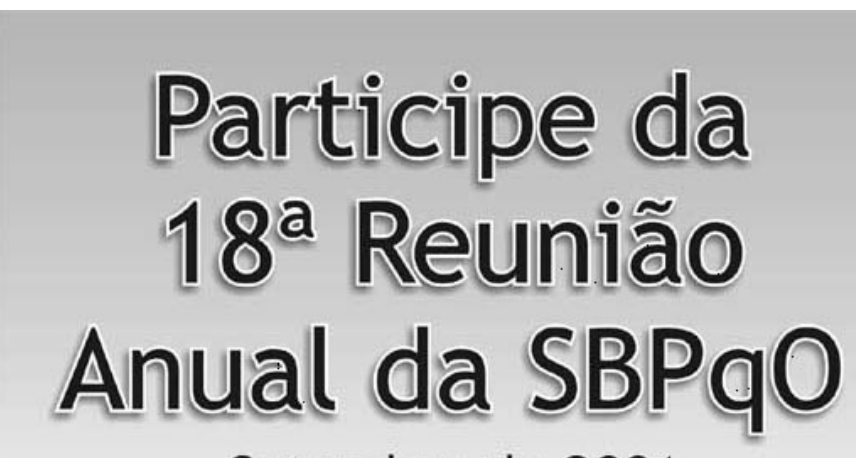

Setembro de 2001

Premiados da $17^{\mathrm{a}}$ reunião Anual da $\mathrm{SBPqO}$
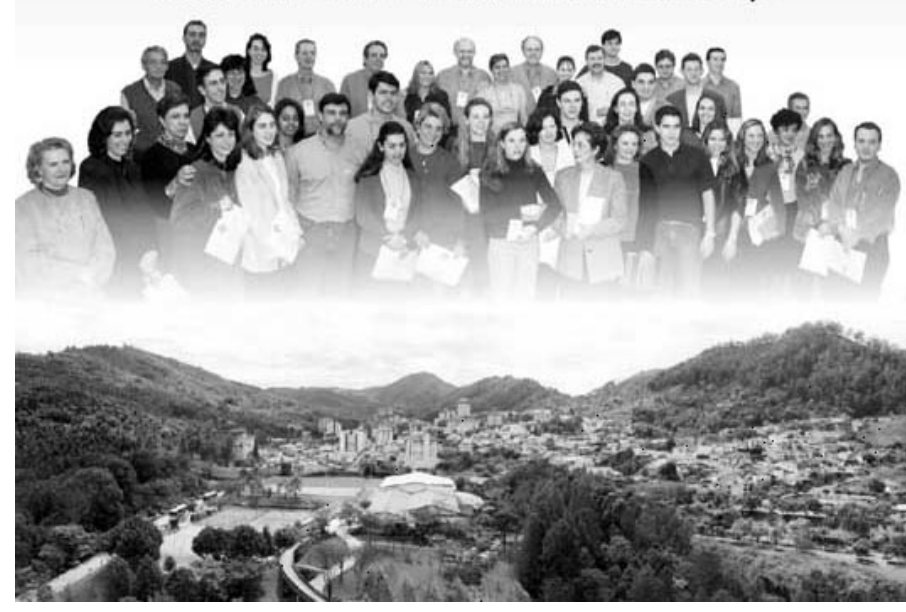
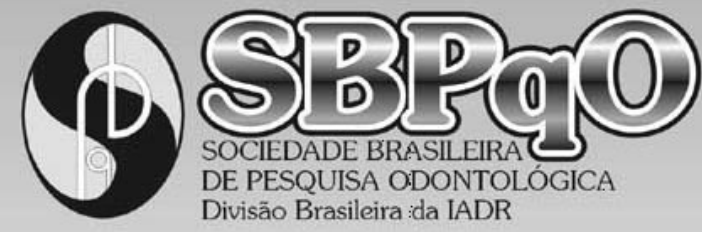

Prêmio E. H Hatton

Prêmio Myaki Issao

Fórum Científico

Projetos de Pesquisa

Consultório Científico

\section{Curso Pré-Congresso}

Sociedade Brasileira de Pesquisa Odontológica Av. Professor Lineu Prestes, 2227 - CEP 05508-900 Cidade Universitária - São Paulo - SP
Tel./Fax: (0**1।) 38|8-7855 - E-mail:sbpqo@sbpqo.org.br www.sbpqo.org.br 